\title{
Hypertension and brain oedema: an experimental study on acute and chronic hypertension in the rat
}

\author{
B A R B R O B OHA NSSON AND LARS-ERIK LINDER \\ From the Departments of Neurology and Anaesthesiology, University of Göteborg, Sweden
}

SUMMARY To determine under what circumstances hypertension is associated with brain oedema, the specific gravity of the brain was measured in acutely hypertensive, renal hypertensive and spontaneously hypertensive rats. Maximum mean arterial pressure (MAP) in acute hypertension induced by intravenous amphetamine or bicuculline was $171 \pm 5$ and $181 \pm 5 \mathrm{mmHg}$ respectively. In spite of pronounced extravasation of Evans blue-albumin, there was no decrease in specific gravity except in the diencephalon in rats given bicuculline $(p<0.05)$. Cortical and cerebellar samples from renal hypertensive rats (MAP $174 \pm 14 \mathrm{mmHg}$ ) were lighter than corresponding regions in normotensive rats $(\mathrm{p}<0.001)$ although the brains showed little or no macroscopic extravasation of Evans blue-albumin. Neither macroscopic protein leakage nor increase in water content was observed in brains from spontaneously hypertensive rats (MAP $210 \pm 5 \mathrm{mmHg}$ ). It is concluded that renal hypertension is more likely to lead to brain oedema than spontaneous genetic hypertension or acute hypertension.

Although it is known from clinical experience as well as from animal studies ${ }^{1}$ that there is a dissociation between albumin leakage and oedema in ischaemic cerebral lesion, extravasation of protein in the brain is often referred to as brain oedema. It is frequently assumed that the permeability increase per se leads to brain oedema, that is an increase in water content of the "vasogenic" type. ${ }^{2}$ Hypertension greatly enhances the tendency for oedema in the presence of traumatic brain lesions, ${ }^{34}$ but it is not clear to what extent a blood-brain barrier (BBB) dysfunction in the absence of tissue damage leads to brain oedema even at high levels of perfusion pressure. Studies on acute hypertension with disturbed BBB function have so far shown no increase in water content unless hypertension was combined with severe hypercapnia. ${ }^{56}$ Likewise, little or no brain oedema has been observed in experimental seizures, a condition with an abrupt increase in blood pressure and pronounced cerebral vasodilatation. ${ }^{7-9}$ It has been suggested that the failure to demonstrate brain oedema in acute hypertension might be due

Address for reprint requests: Dr Barbro Johansson, Department of Neurology, Sahlgrenska sjukhuset, S-413 45 Goteborg, Sweden. Accepted 20 February 1981 to the limited precision of the conventional methods of weighing and drying tissue samples for detecting brain oedema. ${ }^{10}$ Changes in brain water content can be derived from specific gravity measurements provided that the specific gravity of tissue solids remains constant. A sensitive technique to measure changes in brain water content based on determination of the specific gravity in a gradient column has been developed by Nelson et al. ${ }^{11}$ They reported that the range of specific gravity determined by their method was 10-20 times less than that found by weighing whereas the two methods gave the same mean specific gravity value. Several later studies have confirmed the high precision of the gravimetric method in detecting brain oedema. In the present study we used this technique to determine specific gravity of brain tissue in acutely and chronically hypertensive rats. Since vasodilatation enhances protein leakage in the brain during acute hypertension, two drugs which increase the blood pressure and in addition give rise to cerebral vasodilatation were used, that is bicuculline, a drug that provokes seizures $^{12} 13$ and amphetamine. ${ }^{14}$ Renal hypertensive and spontaneously hypertensive rats were studied as models of chronic hypertension. 


\section{Materials and methods}

Male Sprague-Dawley rats (200-300 g) were used except in two groups when the stroke-prone substrain of the Japanese spontaneously hypertensive rats (SHRSP) ${ }^{15}$ and Kyoto Wistar control rats (KWR) were investigated. Only normocapnic animals with $\mathrm{PaO}_{2}>11 \mathrm{kPa}$ were studied. Evans blue, which in vivo binds to serum albumin, was given intravenously $(2 \mathrm{ml} / \mathrm{kg}$ of a $2 \%$ solution) at the start of the experiments. For the number of rats in each group, see the table.

Controls Rats were decapitated under diethyl ether, methohexital or nitrous oxide anaesthesia under conditions comparable to those in the experimental groups, that is they were kept anaesthetised for the same period of time and received the same amount of fluid as the experimental animals. Three of the rats anaesthetised with diethyl ether had indwelling catheters as described for renal hypertensive and spontaneously hypertensive rats.

Amphetamine Anaesthesia was initiated with methohexital (Brietal $\$ 50 \mathrm{mg} / \mathrm{kg}$ ). One femoral artery and one femoral vein were cannulated for anaerobic sampling of blood for blood gas determination, for continuous recording of MAP and for injection of drugs and tracers. The rats were then tracheotomised, relaxed with suxamethonium chloride and ventilated with $75 \% \mathrm{~N}_{2} \mathrm{O}$ in $\mathrm{O}_{2}$ in a rodent respirator (Harvard apparatus). d, l-amphetamine $(5 \mathrm{mg} / \mathrm{kg})$, was given intravenously and the rats were killed by decapitation after an additional dose of methohexital 30 minutes later.

Bicuculline was injected intravenously $(1 \cdot 2 \mathrm{mg} / \mathrm{kg})$. The operative procedure was the same as described for amphetamine. Decapitation was performed when MAP fell below $130-140 \mathrm{mmHg}$, which occurred within 20 minutes after the bicuculline administration in six rats and after 80 and 200 minutes in two rats.

Renal hypertension The left renal artery was constricted to $0.20 \mathrm{~mm}$ by a silver clip under methohexital anaesthesia in rats weighing approximately $175 \mathrm{~g}$. Eight weeks later indwelling catheters were inserted in the aorta from the left femoral artery and in the jugular vein and exteriorised on the back of the neck under methohexital anaesthesia. Two days later the blood pressure was recorded in conscious, unrestrained rats for one hour. If MAP exceeded $160 \mathrm{mmHg}$, Evans blue was injected intravenously and the rats decapitated after intravenous injection of methohexital 2-3 hours later.

Spontaneously hypertensive rats Indwelling catheters were inserted 2 days before killing in SHRSP and control WKR and the rats (10-12 months of age) were treated in the same way as described for renal hypertensive rats.

After decapitation the brains were rapidly removed and immediately immersed in cool kerosene. The specific gravity was determined in a gradient tube made of $250 \mathrm{ml}$ of two different bromobenzenekerosene mixtures of specific gravity 1.0650 and 1.0350 respectively, ${ }^{11}$ the former being continuously diluted by admixture of the latter while poured into a graded glass tube. This was placed in a wider glass tube containing water. Stability of linearity was controlled by standard solutions of $\mathrm{K}_{2} \mathrm{SO}_{4}$ in connection with determination of every sample series. Samples were taken from the cortex, mesencephalon, diencephalon, pons and the cerebellum. To clear the gradient tube, dry $\mathrm{Na}_{2} \mathrm{SO}_{4}$ was used. Statistical differences were evaluated with Wilcoxon's rank sum test.

\section{Results}

Initial MAP and maximum MAP after injection of amphetamine were $135 \pm 7$ and $171 \pm 5 \mathrm{mmHg}$ (mean \pm SEM, see table for the numbers). The corresponding values for rats given bicuculline were $121 \pm 9$ and $181 \pm 5 \mathrm{mmHg}$. MAP in anaesthetised controls was $132 \pm 5 \mathrm{mmHg}$. In conscious, unrestrained renal hypertensive rats MAP was $174 \pm 14 \mathrm{mmHg}$, in SHRSP $210 \pm 5 \mathrm{mmHg}$, in WKR $112 \pm 4 \mathrm{mmHg}$ and in Sprague-Dawley controls $108 \pm 5 \mathrm{mmHg}$. All brains from rats given amphetamine or zicuculline showed areas of Evans blue-albumin extravasation in contrast to

Table Specific gravity of the brain in hypertensive rats compared to control rats

\begin{tabular}{|c|c|c|c|c|c|c|c|}
\hline Experimental group & $n$ & Frontal cortex & Parietal cortex & Diencephalon & Mesencephalon & Pons & Cerebellum \\
\hline Control (S-D) & 12 & $1.0452 \pm 0.0001$ & $1.0452 \pm 0.0002$ & $1.0437 \pm 0.0001$ & $1.0431 \pm 0.0002$ & $1.0423 \pm 0.0001$ & $1.0464 \pm 0.0003$ \\
\hline Control (WKR) & 6 & $1.0452 \pm 0.0001$ & $1.0452 \pm 0.0002$ & $1.0437 \pm 0.0001$ & $1.0430 \pm 0.0001$ & $1.0419 \pm 0.0001$ & $1.0464 \pm 0.0003$ \\
\hline $\begin{array}{l}\text { Acute hypertension } \\
\text { d, l-Amphetamine } \\
\text { (5 } \mathrm{mg} / \mathrm{kg})\end{array}$ & 8 & $1 \cdot 0449 \pm 0 \cdot 0001$ & $1 \cdot 0449 \pm 0 \cdot 0002$ & $1 \cdot 0428 \pm 0.0004$ & $1 \cdot 0427 \pm 0.0002$ & $1.0421 \pm 0.0002$ & $1 \cdot 0461 \pm 0.0003$ \\
\hline $\begin{array}{l}\text { Bicuculline } \\
(1 \cdot 2 \mathrm{mg} / \mathrm{kg})\end{array}$ & 8 & $1.0450 \pm 0.0002$ & $1.0450 \pm 0.0003$ & $1.0431 \pm 0.0002^{*}$ & $1 \cdot 0429 \pm 0.0002$ & $1.0422 \pm 0.0003$ & $1.0450 \pm 0.0010$ \\
\hline Chronic hypertension & & & & & & & \\
\hline $\begin{array}{l}\text { Renal } \\
\text { SHRSP }\end{array}$ & $\begin{array}{l}5 \\
7\end{array}$ & $\begin{array}{l}1.0435 \pm 0.0002 \ddagger \\
1.0455 \pm 0.0001\end{array}$ & $\begin{array}{l}1.0436 \pm 0.0002 \ddagger \\
1.0456 \pm 0.0002\end{array}$ & $\begin{array}{l}1 \cdot 0432 \pm 0.0002 \\
1.0444 \pm 0.0001 \dagger\end{array}$ & $\begin{array}{l}1.0428 \pm 0.0002 \\
1.0439 \pm 0.0001 \dagger\end{array}$ & $\begin{array}{l}1.0418 \pm 0.0003 \\
1.0434 \pm 0.0003 \dagger\end{array}$ & $\begin{array}{l}1.0442 \pm 0.0003 t \\
1.0466 \pm 0.0003\end{array}$ \\
\hline
\end{tabular}

Mean Values \pm SEM. $* p<0.05, \dagger<0.01, \ddagger p<0.001$ for significant difference from control groups (Wilcoxon's rank sum test). SHRSP compared to WKR, the other experimental groups compared to Control (S-D).

Abbreviations: S-D =Sprague-Dawley; WKR = Wistar Kyoto Rats; SHRSP=spontaneously hypertensive rats, stroke-prone. 
control and SHRSP brains which showed on tracer extravasation. Amphetamine induced protein leakage particularly in frontoparietal cortical regions in agreement with earlier description, ${ }^{14}$ whereas bicuculline treated rats had scattered areas of extravasation in the brain with predilection of diencephalic structures. ${ }^{13}$ Three of the five renal hypertensive rats showed a few discrete blue areas of tracer extravasation in cerebral cortex.

The specific gravities of various brain regions of the experimental groups and controls are presented in the table. Since the results showed no difference between the different groups of control rats they were treated together. Rats subjected to acute hypertension by injection of amphetamine or bicuculline did not differ from controls except for a minor decrease in specific gravity in diencephalon in rats given bicuculline $(p<0 \cdot 05)$. Cortical and cerebellar samples from renal hypertensive rats were significantly lighter than controls $(p<0.001)$. Assuming the oedema fluid is water, the increase in tissue volume required to produce a given decrease in specific gravity (sp gr) can be calculated by the following equation ${ }^{11}$ :

$$
\frac{(\mathrm{sp} \mathrm{gr}-1) \text { control- }(\mathrm{sp} \mathrm{gr}-1) \exp \times 100}{(\mathrm{sp} \mathrm{gr}-1) \exp }
$$

$=$ percentage of change of tissue volume. Thus, the specific gravity in cortical regions of renal hypertensive rats indicates 3.9 and $3.7 \%$ increase in volume in frontal and parietal cortex respectively. No increase in water content was observed in SHSP. In fact, the brain stem of these rats had slightly higher specific gravity than WKR controls.

\section{Discussion}

Our results confirm some earlier reports that protein leakage in acute hypertension and experimental seizures may be associated with no or only minor increase in water content. ${ }^{5-9}$ Quantitative data on the extravasation of ${ }^{125} \mathrm{I}$-labelled serum albumin in various types of acute and chronic hypertension have been presented elsewhere. The most extensive extravasation occurs in connection with the acute hypertensive reaction induced by bicuculline or amphetamine. ${ }^{1314}$ The increased permeability in the brain is slight and not consistently present in renal hypertensive rats. ${ }^{16}$ SHR are largely protected as to albumin leakage at high pressure levels, probably due to structural adaptation of arterial vessels. ${ }^{17} 18$ Protein leakage has been observed in SHRSP, but whether this occurs before or after clinical symptoms of stroke is controversial. ${ }^{19} 20$ Our colony of SHRSP develop high blood pressure of a similar magnitude as in Japanese laboratories but have a lower incidence of stroke. The present results with no macroscopic visible extravasation in non-perfused brains does not rule out that a minor leakage may be present. A slight leakage of endogenous serum albumin has been demonstrated in SHRSP with immunoelectrophoresis without concomitant macroscopic Evans blue-albumin extravasation (unpublished observations). The specific gravity in stroke-resistant SHR has been reported not to differ from controls, although no figures were given. ${ }^{21}$ The reason for the slight increase in specific gravity in the brain stem in SHRSP compared to WKR in the present study remains to be elucidated.

With an immunoelectrophoretic technique, the amount of endogenous serum albumin 15-30 minutes after bicuculline administration has been found to be $200-300 \mathrm{ng} / \mathrm{mg}$ brain tissue (wet weight) in the diencephalon and mesencephalon and $60-220 \mathrm{ng} / \mathrm{mg}$ in the cortex. ${ }^{22}$ This amount of albumin would per se have a minor influence on the osmotic pressure of the extracellular fluid, and the effect on brain water will largely be determined by concomitant changes in electrolytes. No direct comparison can be made between the larger protein extravasation in acute hypertension and the smaller but supposedly more longlasting leakage in renal hypertension since the clearance rate of albumin from the tissue is not known. Degradation products of albumin will increase osmotic pressure more than albumin itself, and it has been suggested that ${ }^{125}$ I-labelled serum albumin is rather rapidly degraded in brain tissue. ${ }^{23}$ The fate of endogenous serum albumin in the brain is still largely unknown and, in addition to local degradation, various mechanisms for removal of albumin from the extracellular fluid in the brain have been suggested such as clearing via bulk flow into the cerebrospinal fluid, uptake into astrocytes and back-transport over the cerebral capillaries. ${ }^{24}$

Our data point to differences as to the development of cerebral oedema in renal and spontaneously hypertensive rats. The two models of chronic hypertension differ also with regard to the capacity of the BBB to withstand high levels of intraluminal pressure, ${ }^{16-1825}$ but whether the difference in permeability per se can explain the increased tendency to develop brain oedema in renal hypertension remains to be shown. Having one intact kidney and no clinical symptoms, the rats are not likely to have been uraemic. The urea content in serum of nine renal hypertensive rats 
treated in the same way as in the present series was not significantly higher than in controls eight weeks after the constriction (unpublished observations). Moreover, there is no evidence that uraemia alone increases the water content in the brain. ${ }^{26}{ }^{27}$ In a model of renal hypertension with unilateral constriction of the renal artery and contralateral nephrectomy, Byrom ${ }^{28}$ observed increased brain water content in the cortex only in rats with macroscopic protein leakage and clinical symptoms. The more sensitive method for detecting oedema used in the present study might explain the difference. That brain oedema may occur in the absence of clinical symptoms in chronic hypertension is in agreement with the report by Rosenblum et $a l^{29}$ who found increased water content in unilaterally nephrectomised rats treated with DOCA and salt. It has been reported that unilateral nephrectomy in monkeys increases brain water even in the absence of hypertension and uraemia ${ }^{30}$ but the fact that the remaining kidney was wrapped in cellophane in that study might have been more important than the nephrectomy even if no hypertension developed. The present results indicate that nephrectomy is not a prerequisite for the development of brain oedema in renal hypertension.

The pathogenesis of the clinical syndrome of hypertensive encephalopathy is still not fully understood although the syndrome is correlated to increased cerebrovascular permeability and cerebral oedema. ${ }^{162528}$ It is of interest in this context that the syndrome is more common in patients with renal than with primary (essential) hypertension. Whether this is correlated to a lower degree of structural adaptation of cerebral vessels in renal hypertension or to some additional factor is at present not clear. Some studies suggest a possible role of humoral factors in the pathogenesis of increased permeability and metabolic disturbance in the brain in renal hypertension. ${ }^{16} 3132$ However, further studies are needed to clarify the mechanisms behind brain oedema in renal hypertension.

This work was supported by grants from the Swedish Medical Research Council (project No. 4968), The Medical Faculty of the University of Göteborg and the Swedish National Association against Heart and Chest Disease.

We are most grateful to Dr Stanley $R$ Nelson for instructing us in the use of the specific gravity method. SHRSP were bred in our laboratory from breeding rats kindly supplied by Dr W de Jong, University of Utrecht, The Netherlands.

\section{References}

1 O’Brien MD, Jordan MM, Waltz AG. Ischaemic cerebral edema and the blood-brain barrier. Arch Neurol 1974; 30:461-5.

2 Klatzo I. Neuropathological aspects of brain edema: Presidential Address. J. Neuropath Exp Neurol 1967; 26:1-14.

3 Klatzo I, Wisniewski H, Steinwall O, Streicher E. Dynamics of cold injury edema. In: Klatzo I, Seitelberger F, eds. Brain Edema. New York: Springer, 1967; 554-63.

4 Schutta HS, Kassel NF, Langfitt TW. Brain swelling produced by injury and aggravated by arterial hypertension. Brain 1968; 91:281-94.

5 Johansson BB. Water content in acute arterial hypertension. In: Pappius HM, Feindel W, eds. Dynamics of Brain Edema. Berlin: SpringerVerlag, 1976; 28-31.

6 Meinig G, Reulen HJ, Simon Ch, Hadjidimos A, Schurmann K. Cerebrale Vasoparalyse, arterielle Hypertension and Hirnödem. J Neurol 1975; 211: 25-38.

7 Petito CK, Schaefer JA, Plum F. The bloodbrain barrier in experimental seizures. In: Pappius HM, Feindel W, eds. Dynamics of Brain Edema. Berlin: Springer Verlag, 1976; 38-42.

8 Eisenberg HM, Barlow CF, Lorenzo AV. Effect of dexamethasone on altered brain vascular permeability. Arch Neurol 1970; 23:18-22.

9 Wasterlain CG. Mortality and morbidity from serial seizures. Epilepsia 1974; 15:155-76.

10 Katzman R, Clasen R, Klatzo I, Meyer JS, Pappius HM, Waltz AG. Report of joint committee for stroke resources: IV. Brain edema in stroke. Stroke 1977; 8:512-40.

11 Nelson SR, Mantz M-L, Maxwell JA. Use of specific gravity in the measurement of brain edema. J Appl Physiol 1971; 30:268-71.

12 Meldrum BS, Nilsson B. Cerebral blood flow and metabolic rate early and late in prolonged epileptic seizures induced in rats by bicuculline. Brain 1976; 99:523-42.

13 Johannson B, Nillson B. The pathophysiology of the blood-brain barrier dysfunction induced by severe hypercapnia and by epileptic brain activity. Acta Neuropath (Berl) 1977; 38:153-8.

14 Carlsson C, Johansson BB. Blood-brain barrier dysfunction after amphetamine administration in rats. Acta Neuropath (Berl) 1978; 45:125-9.

15 Okamoto K, Yamori Y, Nagaoka A. Establishment of the stroke-prone spontaneously hypertensive rats. Circulat Res (Suppl I) 1974; 43: $143-53$.

16 Johansson BB, Linder L-E. The blood-brain barrier in renal hypertensive rats. Clin Exp Hypertension 1980; 2:983-93.

17 Johansson BB. Cerebrovascular permeability to protein in spontaneously hypertensive rats after acute blood pressure elevation. Clin Exp Pharmacol Physiol 1976; Suppl 3, 97-100. 
18 Johansson BB. The cerebrovascular permeability to protein after bicuculline and amphetamine administration in spontaneously hypertensive rats. Acta Neurol Scand 1977; 56:399-404.

19 Shibota M, Shino A, Nagaoka A. Cerebrovascular permeability in stroke-prone spontaneously hypertensive rats. Exp Molec Path 1978; 28:330-7.

20 Yamori $\mathbf{Y}$, Horie $\mathbf{R}$, Sato $\mathbf{M}$, Sasagawa $\mathbf{S}$, Okamoto K. Experimental studies on the pathogenesis and prophylaxis of stroke-prone spontaneously hypertensive rats (1). Quantitative estimation of cerebrovascular permeability. Nippon Junkankigaku Shi 1975; 39:611-5.

21 Nelson SR, Dick AR, Buñag RD. Brain edema and blood pressure measurements in unanaesthetized rats with cortical lesions. In: Pappius HM, Feindel W, eds. Dynamics of Brain Edema. Berlin: Springer-Verlag, 1976; 77-82.

22 Persson LI, Rosengren LE, Johansson BB. Albumin extravasation in bicuculline induced blood-brain barrier dysfunction. A comparison between endogeneous and ${ }^{125}$ I-labelled exogenous albumin. Acta Neurol Scand 1980; 62:259-62.

23 Lorenzo AV, Shirahige I, Liang M, Barlow F. Temporary alteration of cerebrovascular permeability to plasma protein during drug-induced seizures. Amer J Physiol 1972; 223:268-77.

24 Pappius HM, Feindel W, eds. Dynamics of Brain Edema. Berlin: Springer-Verlag, 1976.

25 Johansson BB. The blood brain barrier in acute and chronic hypertension. In: Eisenberg HM,
Suddith RL, eds. The Cerebral Microvasculature. Investigation of the Blood-Brain Barrier. New York: Plenum Press. Adv Exp Med Biol 1980; 131:211-226.

26 Olsen S. The brain in uremia. Acta Psychiat Neurol Scand 1961; 26: Suppl 156: 1-122.

27 Fishman RA, Raskin NH. Experimental uremic encephalopathy. Permeability and electrolyte metabolism of brain and other tissues. Arch Neurol 1967; 17:10-21.

28 Byrom FB. The pathogenesis of hypertensive encephalopathy and its relation to the malignant phase of hypertension: experimental evidence from the hypertensive rat. Lancet 1964; 2:201211.

29 Rosenblom WI, Donnenfelt H, Aleu F. Effects of increased blood pressure on cerebral vessels in mice. Arch Neurol 1966; 14:631-43.

30 Anderson DC, Jordan MM, Jacobson RL, Hayakawa T, Waltz AC. Brain water alterations after unilateral nephrectomy. Stroke 1977; 8: 462-7.

31 Fujishima $M$, Onoyama K, Iniki $H$, Ogata $S$, Omae T. Effects of acute hypertension on brain metabolism in normotensive, renovascular hypertensive and spontaneously hypertensive rats. Stroke 1978; 9:349-53.

32 Giacomelli F, Rooney J, Wiener J. Cerebrovascular ultrastructure and permeability after carotid artery constriction in experimental hypertension. Exp Molec Path 1978; 28:309-21. 